\title{
Effect of food intake on left ventricular wall stress
}

\author{
Ylva Gårdinger ${ }^{1,2^{*}}$, Joanna Hlebowicz ${ }^{3}$, Ola Björgell ${ }^{2}$ and Magnus Dencker ${ }^{1}$
}

\begin{abstract}
Objective: Left ventricular wall stress has been investigated in a variety of populations, but the effect of food intake has not been evaluated. We assessed whether left ventricular wall stress is affected by food intake in healthy subjects.

Methods: Twenty-three healthy subjects aged $25.6 \pm 4.5$ years were investigated. Meridional end-systolic wall stress (ESS) and circumferential end-systolic wall stress (CESS) were measured before, 30 minutes after, and 110 minutes after a standardised meal.

Results: Both ESS and cESS decreased significantly $(P<0.001)$ from fasting values 30 minutes after the meal, and had not returned to baseline after 110 minutes. ESS decreased from $65 \pm 16 \mathrm{kdynes} / \mathrm{cm}^{2}$ (fasting) to $44 \pm 12$ $\mathrm{kdynes} / \mathrm{cm}^{2} 30$ minutes after, and to $58 \pm 13 \mathrm{kdynes} / \mathrm{cm}^{2} 110$ minutes after eating. cESS decreased from $98 \pm 24$ $\mathrm{kdynes} / \mathrm{cm}^{2}$ to $67 \pm 18 \mathrm{kdynes} / \mathrm{cm}^{2} 30$ minutes after, and to $87 \pm 19 \mathrm{kdynes} / \mathrm{cm}^{2} 110$ minutes after the meal.
\end{abstract}

Conclusion: This study shows that left ventricular wall stress is affected by food intake in healthy subjects.

Keywords: Food intake, Echocardiography, Wall stress

\section{Introduction}

End-systolic wall stress has been used as a measurement of myocardial afterload, the counter force limiting left ventricular ejection. To put it simply, circumferential fiber shortening is limited by circumferential end-systolic wall stress (cESS), whereas longitudinal fiber shortening is limited by meridional end-systolic wall stress (ESS) [1,2]. Left ventricular wall stress has been examined in a number of populations, for example in patients with hypertensive heart disease [3,4], in patients with type 1 diabetes mellitus [5] and patients under treatment with beta-1 blockers [6]. Wall stress has also been shown to have prognostic value [4]. Digestion of food is known to significantly alter hemodynamics [7-10] and may therefore affect wall stress, as loading conditions are altered. The purpose of the present study is to evaluate the hypothesis that food intake, in healthy volunteers, may have an effect on meridional and circumferential wall stress, as this has not previously been investigated.

\footnotetext{
* Correspondence: ylva.gardinger@skane.se

'Department of Clinical Sciences, Unit of Clinical Physiology and Nuclear

Medicine, Skåne University Hospital, Lund University, Malmö, Sweden

${ }^{2}$ Department of Clinical Sciences, Unit of Radiology, Skåne University

Hospital, Lund University, Malmö, Sweden

Full list of author information is available at the end of the article
}

\section{Methods}

\section{Study population}

Study subjects were comprised of 23 healthy volunteers (11 male and 12 female aged $25.6 \pm 4.5$ years). No subjects had symptoms or history of cardiovascular disease or any other chronic diseases. None of the subjects were taking cardiovascular medication. Other exclusion criteria were inappropriate acoustic windows and nonsinus rhythm.

\section{Procedures}

The examinations were performed in the morning after fasting overnight. Height and body mass were measured, and body mass index was calculated. The following formula was used to calculate body surface area (BSA): (height in $\mathrm{cm}$ ) $0.725 \times$ (body mass in $\mathrm{kg}$ ) $0.452 \times 0.00718$ [11]. Blood pressure (BP) and resting heart rate were measured in the supine position after 15 minutes of rest. BP was measured by a conventional (mechanical) sphygmomanometer with aneroid manometer and stethoscope. Systolic pressure (SBP) (first phase) was identified with the first of the continuous Korotkoff sounds. Diastolic pressure was identified at the moment the Korotkoff sounds disappear (fifth phase). A baseline echocardiographic exam was performed, after which the subjects ingested a standardised meal consisting of $300 \mathrm{~g}$ rice pudding (AXA 
Goda Gröten Risgrynsgröt; Lantmännen AXA, Järna Sweden). A second echocardiographic exam was performed 30 minutes after, and a third exam 110 minutes after the meal. The subjects reassumed a supine position between the echocardiographic examinations. The study was approved by the Central Ethical Review Board Lund, Sweden.

\section{Echocardiography}

After an initial screening examination to rule out cardiac dysfunction, a transthoracic echocardiographic examination was performed before, 30 minutes, and $110 \mathrm{mi}$ nutes after the meal, with Sonos 5500 (Philips, Andover, MA, USA) in left lateral position, after 15 minutes rest. A single observer performed all echocardiographic measurements three times on separate cardiac cycles, and the mean value was used in analyses. Repeated measurements in all subjects were performed to assess intra-observer reproducibility. In 2D guided M-mode echocardiography from parasternal long axis view, the left ventricular internal dimension in diastole (LVIDd) and systole (LVIDs) and the posterior wall thickness in systole (PWTs) were measured with the ultrasound beam at or just below the tips of mitral valve leaflets. The measurements were made according to the American Society of Echocardiography guidelines [12].

Meridional end-systolic stress was calculated using the following formula, which is invasively validated, [3,13] where SBP is systolic blood pressure.

$$
\mathrm{ESS}=\frac{0.334 \times \mathrm{SBP} \times \text { LVIDs }}{\text { PWTs } \times\{1+(\text { PWTs } / \text { LVIDs })\}}
$$

Circumferential end-systolic stress was also estimated from M-mode tracings as previously described [3,14].

$$
\mathrm{cESS}=\frac{\mathrm{SBP} \times(\mathrm{LVIDs} / 2)^{2} \times\left\{1+\frac{(\mathrm{LVIDs} / 2+\mathrm{PWTs})^{2}}{(\mathrm{LVIDs} / 2+\mathrm{PWTs} / 2)^{2}}\right\}}{(\mathrm{LVIDs} / 2+\mathrm{PWTs})^{2}-(\mathrm{LVIDs} / 2)^{2}}
$$

\section{Statistical analysis}

Data are presented as mean \pm standard deviation (SD). Statistical analyses were performed using Statistica 7.1 (StatSoft Inc, Tulsa, OK, USA). Comparisons between fasting values for ESS and cESS, versus values 30 and $110 \mathrm{mi}-$ nutes after the ingestion of food, were analyzed for significance with Wilcoxon matched pairs test. Statistical significance was set at a level of $\mathrm{P}<0.05$.

\section{Results}

All subjects had complete measurements, and no subjects were found to have any cardiac dysfunction. Table 1 displays descriptive statistics of the study population and cardiac dimensions.
Table 1 Subjects' anthropometric characteristics and cardiac dimensions $(\mathbf{n}=\mathbf{2 3})$

\begin{tabular}{ll}
\hline Variable & \\
\hline Sex $($ male/female) & $11 / 12$ \\
Body mass $(\mathrm{kg})$ & $68 \pm 11$ \\
Height $(\mathrm{cm})$ & $177 \pm 8$ \\
BMI $\left(\mathrm{kg} / \mathrm{m}^{2}\right)$ & $21.7 \pm 2.2$ \\
BSA $\left(\mathrm{m}^{2}\right)$ & $1.8 \pm 0.2$ \\
LVIDd $\left(\mathrm{mm} / \mathrm{m}^{2}\right)$ & $26.7 \pm 1.9$ \\
LVIDs $\left(\mathrm{mm} / \mathrm{m}^{2}\right)$ & $17.7 \pm 1.9$ \\
IVSd $\left(\mathrm{mm} / \mathrm{m}^{2}\right)$ & $5.1 \pm 0.4$ \\
PWTd $\left(\mathrm{mm} / \mathrm{m}^{2}\right)$ & $5.0 \pm 0.4$ \\
PWTs $\left(\mathrm{mm} / \mathrm{m}^{2}\right)$ & $6.9 \pm 0.9$ \\
LA $\left(\mathrm{mm} / \mathrm{m}^{2}\right)$ & $18.2 \pm 1.9$ \\
LVM $\left(\mathrm{g} / \mathrm{m}^{2}\right)$ & $87.6 \pm 18.1$ \\
\hline Vas $\mathrm{ar} \mathrm{m}$ &
\end{tabular}

Values are mean \pm SD.

Abbreviations: Indexed for BSA: left ventricular internal dimension in diastole (LVIDd), left ventricular internal dimension in systole (LVIDs), interventricular septum thickness in diastole (IVSd), posterior wall thickness in diastole (PWTd), posterior wall thickness in systole (PWTs), left atrial end-systolic diameter (LA), and left ventricular mass (LVM). Body surface area (BSA).

The mean value for PWTs increased 30 minutes after food intake, and had almost returned to the fasting value 110 minutes after eating. The mean value for LVIDs decreased 30 minutes after the meal, and was still somewhat below the fasting value after 110 minutes. Systolic BP was not significantly altered after food intake, whereas diastolic BP decreased from $66 \pm 7 \mathrm{mmHg}$ fasting to $58 \pm 7 \mathrm{mmHg}$ 30 minutes after the meal, and $63 \pm 6 \mathrm{mmHg} 110$ minutes after food intake. Both ESS and cESS decreased significantly $(\mathrm{P}<0.001)$ from fasting values 30 minutes after the meal, and had not returned to baseline values 110 minutes after food intake (Figures 1 and 2). Both ESS and cESS were found to decrease $32 \% 30$ minutes after the meal, and 110 minutes after food intake these values were still decreased by $11 \%$, compared to fasting values (Table 2). Intra-observer variability was $10 \%$ for both ESS and cESS.

\section{Discussion}

This study shows that left ventricular wall stress is affected by food intake, and even 110 minutes after food intake, wall stress had not returned to fasting values. Since hemodynamics is known to change postprandially, it is not unreasonable that wall contractility would also be altered accordingly.

In our study population, systolic BP was not significantly altered after a meal, whereas both posterior wall thickness (PWTs) and ventricular inner diameter (LVIDs) changed, resulting in significant changes in both meridional- and circumferential end-systolic wall stress. Thus, the findings are not driven by blood pressure but by myocardial contractility. The mechanisms behind the findings in the 


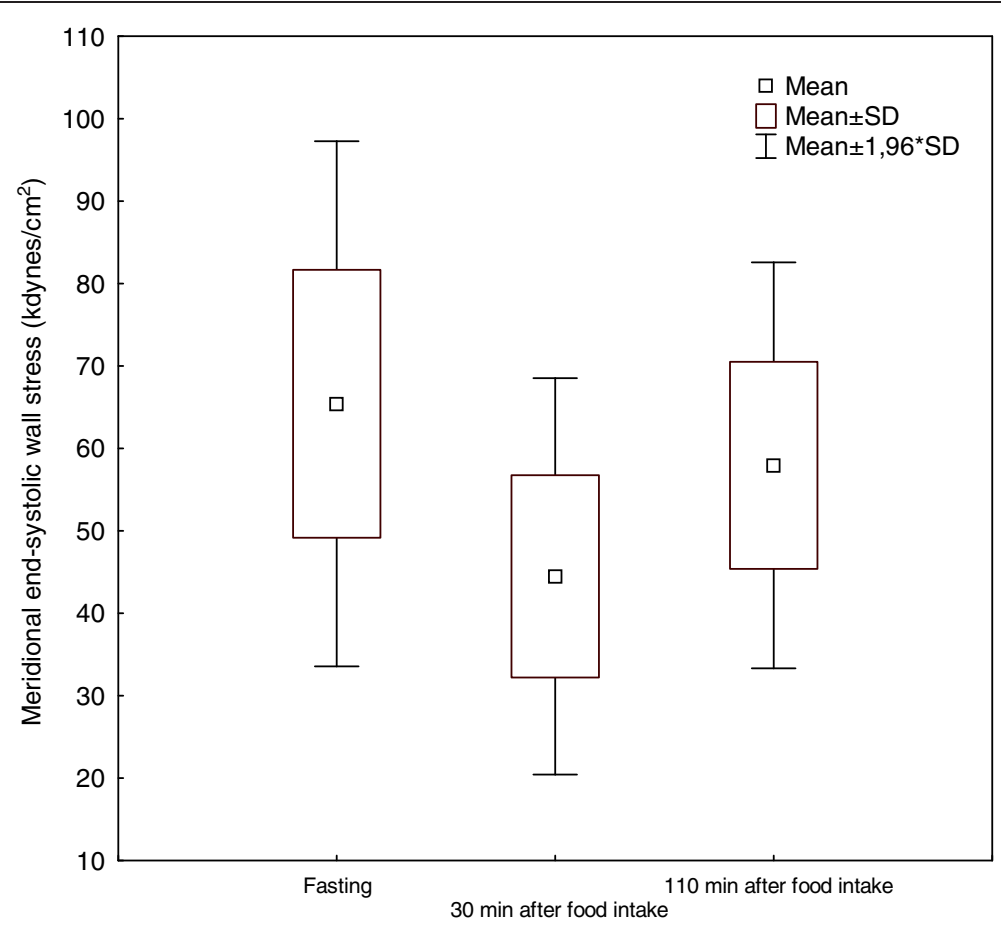

Figure 1 Meridional end-systolic wall stress before, 30 minutes after, and 110 minutes after the meal.

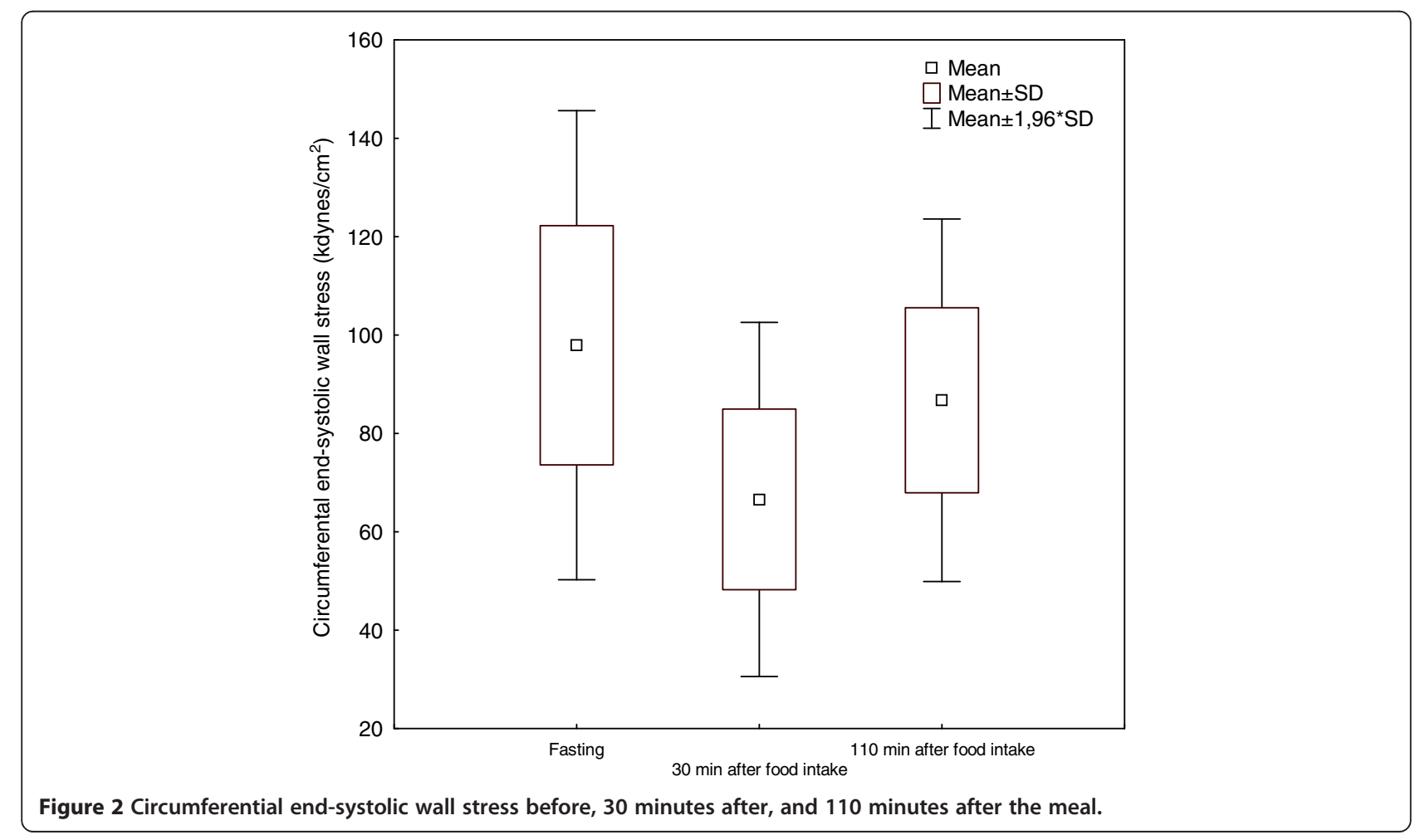


Table 2 Hemodynamics, blood pressure and heart rate parameters before, $\mathbf{3 0}$ minutes after, and 110 minutes after a standardized meal $(\mathbf{n}=\mathbf{2 3})$

\begin{tabular}{llll}
\hline Variable & Fasting & $\mathbf{3 0}$ minutes after food intake & $\mathbf{1 1 0}$ minutes after food intake \\
\hline ESS $\left(\mathrm{kdynes} / \mathrm{cm}^{2}\right)$ & $65 \pm 16$ & $44 \pm 12^{* * *}$ & $58 \pm 13^{*}$ \\
CESS $\left(\mathrm{kdynes} / \mathrm{cm}^{2}\right)$ & $98 \pm 24$ & $67 \pm 18^{* * *}$ & $87 \pm 19^{* *}$ \\
LVIDs $(\mathrm{mm})$ & $32 \pm 3$ & $28 \pm 4^{* * *}$ & $31 \pm 3^{*}$ \\
PTWs $(\mathrm{mm})$ & $12.6 \pm 2.0$ & $14.7 \pm 2.1^{* * *}$ & $13.2 \pm 1.7$ \\
IVSs $(\mathrm{mm})$ & $12.9 \pm 1.8$ & $15.3 \pm 2.0^{* * *}$ & $13.7 \pm 1.9$ \\
Heart rate $(\mathrm{bpm})$ & $60 \pm 8$ & $64 \pm 10^{* *}$ & $60 \pm 10$ \\
Systolic BP $(\mathrm{mmHg})$ & $103 \pm 9$ & $102 \pm 10$ & $102 \pm 9$ \\
Diastolic BP $(\mathrm{mmHg})$ & $66 \pm 7$ & $58 \pm 7^{* * *}$ & $63 \pm 6^{*}$
\end{tabular}

Values are mean \pm SD.

Abbreviations: Blood pressure (BP), meridional end-systolic wall stress (ESS), circumferential end-systolic wall stress (cESS), left ventricular inner diameter in systole (LVIDs), posterior wall thickness in systole (PWTs), and septal wall thickness in systole (IVSs). Please observe that values for cardiac size are reported in absolute values.

*Indicates significant difference $(P<0.05)$, compared to fasting values.

**Indicates significant difference $(P<0.01)$, compared to fasting values.

***Indicates significant difference $(P<0.001)$, compared to fasting values.

present investigation are not known. Several kinds of postprandial cardiovascular changes have, however, been reported in the literature. Postprandial cardiac output increase has been suggested to result from increases in blood flow in the superior mesenteric artery, the heart rate and stroke volume [9]. Physiological changes in the levels of glucose, insulin, GLP-1 and ghrelin may also influence the activity of the heart [15]. Moreover, it is known that insulin has positive chronotropic and inotropic effects on the heart [16], and the hormone glucagon-like peptide 1 has been shown to increase left ventricular function $[17,18]$. The hormone ghrelin has been shown to increase cardiac output and stroke volume [19-22].

As end-systolic wall stress has been used as a measurement of myocardial afterload, it is not surprising that changes are seen after food intake. The effect of food intake on left ventricular wall stress has not been investigated previously. The effect of alterations in loading condition on left ventricular wall stress has, however, been investigated by means of fluid loading and application of sublingual glyceryl trinitrate in a population of patients that were undergoing routine coronary angiography [23]. Fluid loading increased wall stress, and application of glyceryl trinitrate decreased wall stress. This corresponds well to the hypothesis of postprandial hemodynamic changes affecting wall stress.

Left ventricular wall stress and mid-wall mechanics have been used to investigate different populations, including patients with ventricular hypertrophy [24], hypertensive heart disease [3,4], diabetes [5], and patients undergoing treatment with beta blockers [6]. There have also been studies investigating age-related changes in wall stress $[25,26]$. The time frames between food intake and echocardiographic examinations have, however, not been specified in these studies, suggesting that this was not controlled. The change in left ventricular wall stress seen after food intake are about the same magnitude as the differences seen between different populations (for example, athletes or hypertensive subjects versus controls) in some investigations $[3,24]$. While it is difficult to control patients' food intake in clinical echocardiography, one should be aware of the effect that food intake has on these echocardiographic parameters, affecting in this case both ESS and cESS. The influence of food consumption should be considered in studies, especially when a small sample size is involved.

This investigation was limited by our inability to perform the echocardiographic exams blinded to the state of food intake, because a single observer performed all exams. In an attempt to avoid bias, all exams were stored digitally and the measurements were performed later in random order. The change in left ventricular wall stress had not yet returned to baseline values 110 minutes after food intake, and in hindsight we would have chosen a longer time period after eating. Moreover, we did not include a control group who did not receive the prepared meal after overnight fasting. The present study showed the effect of food intake only in young, healthy subjects. Additional studies are warranted in older healthy subjects and in patients with various health conditions to determine whether the findings in the present investigation are reproducible in such populations. Further studies are also needed to evaluate the time frame necessary for measurements to return to baseline values.

\section{Conclusion}

This study shows that left ventricular wall stress is affected by food intake in healthy subjects. 


\section{Competing interests}

The authors declare that they have no competing interests.

\section{Authors' contributions}

The authors' contributions were as follows: JH, OB and MD designed the study. $J \mathrm{H}$ was responsible for recruiting the subjects. MD performed the echocardiographic examinations. YG and MD carried out the statistical calculations. YG wrote the first draft of the manuscript, all authors made critical revisions of the manuscript. All authors read and approved the final manuscript.

\section{Author details}

'Department of Clinical Sciences, Unit of Clinical Physiology and Nuclear Medicine, Skåne University Hospital, Lund University, Malmö, Sweden. ${ }^{2}$ Department of Clinical Sciences, Unit of Radiology, Skåne University Hospital, Lund University, Malmö, Sweden. ${ }^{3}$ Department of Clinical Sciences, Division of Medicine, Skåne University Hospital, Lund University, Malmö, Sweden.

Received: 11 October 2013 Accepted: 24 January 2014

Published: 28 January 2014

\section{References}

1. Quinones MA, Gaasch WH, Cole JS, Alexander JK: Echocardiographic determination of left ventricular stress-velocity relations. Circulation 1975, 51:689-700.

2. Grossman W, Jones D, McLaurin LP: Wallstress and patterns of hypertrophy in the human left ventricle. J Clin Invest 1975, 56:56-64.

3. de Simone G, Devereux R, Roman M, Ganau A, Saba P, Alderman M, Laragh J: Assessment of left ventricular function by the midwall fractional shortening/end-systolic stress relation in human hypertension. J Am Coll Cardiol 1994, 23:1444-1451.

4. De Simone G, Devereux RB, Koren MJ, Mensah GA, Casale PN, Laragh JH: Midwall left ventricular mechanics. An independent predictor of cardiovascular risk in arterial hypertension. Circulation 1996, 93:259-265.

5. Palmieri V, Capaldo B, Russo C, laccarino M, Di Minno G, Riccardi G, Celentano A: Left ventricular chamber and myocardial systolic function reserve in patients with type 1 diabetes mellitus: insight from traditional and doppler tissue imaging echocardiography. J Am Soc Echocardiogr 2006, 19:848-856.

6. Palmieri V, Russo C, Palmieri EA, Pezzullo S, Celentano A: Changes in components of left ventricular mechanics under selective beta-1 blockade: insight from traditional and new technologies in echocardiography. Eur J Echocardiogr 2009, 10:745-752.

7. Fagan TC, Sawyer PR, Gourley LA, Lee JT, Gaffney TE: Postprandial alterations in hemodynamics and blood pressure in normal subjects. Am J Cardiol 1986, 58:636-641.

8. Waaler BA, Eriksen M, Janbu T: The effect of a meal on cardiac output in man at rest and during moderate exercise. Acta Physiol Scand 1990, 140:167-173.

9. Waaler BA, Eriksen M, Toska K: The effect of meal size on postprandial increase in cardiac output. Acta Physiol Scand 1991, 142:33-39.

10. Dencker M, Björgell O, Hlebowicz J: Effect of food intake on commonly used pulsed doppler and tissue doppler measurements. Echocardiography 2011, 28:843-847.

11. Du Bois D, Du Bois EF: A formula to estimate the approximate surface area if height and weight be known. Arch Intern Med 1916, 7:863-871.

12. Sahn DJ, De Maria A, Kisslo J, Weyman A: The committee on M-mode standardization of the American Society of Echocardiography: recommendations regarding quantitation in M-mode echocardiography. Results of a survey of echocardiographic mesurements. Circulation 1978, 58:1072-1083.

13. Reichek N, Wilson J, St John Sutton M, Plappert TA, Goldberg S, Hirshfeld JW: Noninvasive determination of left ventricular end-systolic stress. Validation of the method and initial application. Circulation 1982, 65:99-109.

14. Gaasch WS, Zile MR, Hosino PK, Apstein CS, Blaustein AS: Stress-shortening relations and myocardial blood flow in compensated and failing canine hearts with pressure overload hypertrophy. Circulation 1989, 79:872-873.

15. Hebowicz J, Lindstedt S, Björgell O, Dencker M: The effect of endogenously released glucose, insulin, glucagon-like peptide 1, ghrelin on cardiac output, heart rate, stroke volume, and blood pressure. Cardiovasc Ultrasound 2011, 9:43.

16. Baron AD: Hemodynamic actions of insulin. Am J Physiol 1994, 267:187-202.
17. Nikolaidis LA, Mankad S, Sokos GG, Miske G, Shah A, Elahi D, Shannon RP: Effects of glucagon-like peptide-1 in patients with acute myocardial infarction and left ventricular dysfunction after successful reperfusion. Circulation 2004, 109:962-965.

18. Sokos GG, Nikolaidis LA, Mankad S, Elahi D, Shannon RP: Glucagon-like peptide-1 infusion improves left ventricular ejection fraction and functional status in patients with chronic heart failure. J Card Fail 2006, 212:694-699.

19. Nagaya N, Kojima M, Uematsu M, Yamagishi M, Hosoda H, Oya H, Hayashi Y, Kangawa K: Hemodynamic and hormonal effects of human ghrelin in healthy volunteers. Am J Physiol Regul Integr Comp Physiol 2010, 280:1483-1487.

20. Nagaya N, Miyatake K, Uematsu M, Oya H, Shimizu W, Hosoda H, Kojima M, Nakanishi N, Mori H, Kangawa K: Hemodynamic, renal, and hormonal effects of ghrelin infusion in patients with chronic heart failure. J Clin Endocrinol Metab 2010, 86:5854-5859.

21. Nagaya N, Moriya J, Yasumura Y, Uematsu M, Ono F, Shimizu W, Ueno K, Kitakaze M, Miyatake K, Kangawa K: Effects of ghrelin administration on left ventricular function, exercise capacity, and muscle wasting in patients with chronic heart failure. Circulation 2004, 110:3674-3679.

22. Nagaya N, Moriya J, Yasumura Y, Uematsu M, Ono F, Shimizu W, Ueno K, Kitakaze M, Miyatake K, Kangawa K: Effects of glucagon-like peptide-1 in patients with acute myocardial infarction and left ventricular dysfunction after successful reperfusion. Circulation 2004, 109:962-965.

23. Burns AT, La Gerche A, D'hooge J, Maclsaac Al, Prior DL: Left ventricular strain and strain rate: characterization of the effect of load in human subjects. Eur J Echocardiogr 2010, 11:283-289.

24. Mayet J, Ariff B, Wasan B, Chapman N, Shahi M, Senior R, Foale RA, McG Thom SA: Midwall myocardial shortening in athletic left ventricular hypertrophy. Int J Cardiol 2002, 86:233-238.

25. De Simone G, Kimball TR, Roman MJ, Daniels SR, Celentano A, Witt SA, Devereux RB: Relation of left ventricular chamber and midwall function to age in normal children, adolescents and adults. Ital Heart J 2000, 1:295-300.

26. Crepaz R, Cemin R, Pedron C, Gentili L, Trevisan D, Pitscheider W: Agerelated variations of left ventricular endocardial and midwall function in healthy infants, children and adolescents. Ital Heart J 2005, 6:634-639.

doi:10.1186/1476-7120-12-2

Cite this article as: Gårdinger et al:: Effect of food intake on left ventricular wall stress. Cardiovascular Ultrasound 2014 12:2.

\section{Submit your next manuscript to BioMed Central and take full advantage of:}

- Convenient online submission

- Thorough peer review

- No space constraints or color figure charges

- Immediate publication on acceptance

- Inclusion in PubMed, CAS, Scopus and Google Scholar

- Research which is freely available for redistribution 